\title{
Enhanced of thermoelectric properties and effects of Sb doping on the electrical properties of $\mathrm{Tl}_{10^{-}}$ ${ }_{x} \mathrm{Sb}_{\mathrm{x}} \mathrm{Te}_{6}$ nano-particles
}

\author{
Waqas M. Khan ${ }^{1}$, Wiqar H. Shah ${ }^{1}$, Sabir Khan ${ }^{1}$, Sufaid Shah ${ }^{1}$, Waqar A. Syed ${ }^{1}$, Akif Safeen², Kashif Safeen ${ }^{3}$ \\ ${ }^{1}$ Department of Physics, Faculty of Basic and Applied Sciences, International Islamic University, Islamabad 46000, Pakistan \\ ${ }^{2}$ Department of Physics, University of Poonch, Rawalakot, AJK 12350, Pakistan \\ ${ }^{3}$ Department of Physics, Abdul Wali Khan University, Mardan 23200, Pakistan
}

Corresponding Author Email: wiqarhussain@yahoo.com

https://doi.org/10.18280/ijht.360224

Received: 6 October 2017

Accepted: 23 April 2018

\begin{abstract}
Keywords:
Sb-doped tellurium telluride nanomaterials, electron holes competition, seebeck co-efficient, electrical conductivity, power factor
\end{abstract}

\begin{abstract}
We have prepared the thallium antimony telluride with different doping concentration of $\mathrm{Sb}$, $\mathrm{Tl}_{10^{-} \mathrm{x}} \mathrm{Sb}_{\mathrm{x}} \mathrm{Te}_{6}(\mathrm{x}=1,1.25,1.50,1.75,2)$ using solid state reaction techniques. Furthermore, Nano-particles were prepared from the ingot of the respective compound by ball milling techniques. X-rays diffraction analysis confirmed the phase purity of the compound, as no extra peaks were observed. The miller indices and lattice constant has been determined from the XRD data. Energy dispersive X-rays spectroscopy result confirmed the stoichiometric elemental composition of $\mathrm{Tl}_{10^{-}} \mathrm{Sb}_{\mathrm{x}} \mathrm{Te}_{6}$ compound. With increasing antimony (Sb) content the Seebeck coefficient $(\mathrm{S})$ was increased, due to the affected electron hole ratio in the system. The contrary behavior of Seebeck co-efficient and electrical conductivity give rise to enhancement in power factor. Our study allows envisaging the application of $\mathrm{Tl}_{10^{-} \mathrm{x}} \mathrm{Sb}_{\mathrm{x}} \mathrm{Te}_{6}$ as one of the suitable materials for thermoelectric generator.
\end{abstract}

\section{INTRODUCTION}

Achieving large thermoelectric efficient system using a low-cost material, with an appreciable degree of compatibility with the modern technology is need of the time. Keeping in view the progressively of depletion of fossil fuel sources, alternate energy sources, particularly with thermoelectric materials, become increasingly important. These materials are capable of converting thermal energy from a temperature gradient into electrical energy (Seebeck effect) or convert electrical energy into a temperature gradient. (Peltier effect) The Seebeck effect has gained significant interests for application in automotive industry, where the energy from the waste heat could be converted to electrical energy.

The performance of a material for thermoelectric applications is determined by the dimensionless figure of merit ZT [1], where $T$ is the absolute temperature and $Z=\left(S^{2} \sigma\right) / \kappa$ where (' $S$ ' is the Seebeck coefficient, ' $\sigma$ ' the electrical conductivity, and ' $\kappa$ ' the thermal conductivity).

The first two quantities need to be as big as possible, while the last one need to be small and should be able to maintain the temperature difference between the hot and cold side. The problem is that all three quantities are inter-related, and cannot be optimized independently. Desirable thermoelectric materials must have large Seebeck coefficient, high electrical conductivity, and low thermal conductivity to preserve the heat at the junction and reduce the heat transport losses.

Thallium telluride's or thallium Antimonides consist of large group of compounds with complex crystal structures, i.e $\mathrm{Tl}_{2} \mathrm{SnTe}_{5}$ [2], $\mathrm{Ag}_{9} \mathrm{TlTe}_{5}$ [3], Tl-filled skutterudites [4, 5], and $\mathrm{Tl}_{\mathrm{S}} \mathrm{bTe} \mathrm{T}_{2}$. More specifically, some ternary groups of $\mathrm{Tl}_{5} \mathrm{Te}_{3}$ are more useful such as $\mathrm{Tl}_{9}(\mathrm{Bi} / \mathrm{Sb}) \mathrm{Te}_{6}[6,7], \mathrm{Tl}_{9}(\mathrm{Sn} / \mathrm{Pb}) \mathrm{Te}_{6}[8,9]$ and $\mathrm{Tl}_{4}(\mathrm{Sn} / \mathrm{Pb}) \mathrm{Te}_{3}[10,11]$ exhibit good thermoelectric properties. In the present study, we have studied Thallium
Antimony Telluride, $\mathrm{Tl}_{10-\mathrm{x}} \mathrm{Sb}_{\mathrm{x}} \mathrm{Te}_{6}$, based nano materials with similar behavior as of $\mathrm{Tl}_{4} \mathrm{ZrTe}_{4}$ [12], $\mathrm{Tl}_{2} \mathrm{ZrTe}_{3}$ [13] and good thermoelectric properties like $\mathrm{Tl}_{9} \mathrm{SnTe}_{6}$ and $\mathrm{Tl}_{9} \mathrm{BiTe}{ }_{6}$ systems. The same phenomenon group I $4 / \mathrm{mcm}$ and also in iso-structurl to $\mathrm{Tl}_{5} \mathrm{Te}_{3} \equiv \mathrm{Tl}_{10} \mathrm{Te}_{6}$ with different ratio of $\mathrm{Tl}$ and $\mathrm{Sb}$ elements [14]. The power factor for $\mathrm{Tl}_{10-\mathrm{x}} \mathrm{Sb}_{\mathrm{x}} \mathrm{Te}_{6}$ nano materials is obtained in the range of 4.4-8.9 $\mu \mathrm{Wcm}^{-1} \mathrm{~K}^{-2}$ which is in good agreement with $\mathrm{Tl}_{4} \mathrm{PbTe}_{3}-\mathrm{Tl}_{9} \mathrm{PbTe}_{6}$ i.e. 5.2 - $6.2 \mu \mathrm{Wcm}^{-1} \mathrm{~K}^{-2}$ at $685 \mathrm{~K}[9,15]$.

The main objective of this work is to optimize the temperature dependence of the thermoelectric properties of $\mathrm{Sn}$ doped Tellurium Telluride $\mathrm{Tl}_{10-\mathrm{x}} \mathrm{Sb}_{\mathrm{x}} \mathrm{Te}_{6}$ over a wide temperature range and evaluates their potential for thermoelectric power generator. The purposes and importance of this study is to see the effects of charge carrier's concentrations on the Seebeck co-efficient, electrical conductivity and, power factor different dopants on thallium telluride nano-system. In order to develop high-performance nano-thermoelectric materials, we have investigated thallium nano-particles as these types of nano-materials have extremely low thermal conductivity as well as moderate electrical performance [16].

We have studied the effect of induction/reduction of the charge carriers on thermal and transport characteristics using different dopants content. The charge carrier's concentration affects the ratio of electron-hole concentration which in turns increases the electron scattering in the chalcogenide system consequently affecting the electrical conductivity and thermopower. We have investigated the properties of $\mathrm{Tl}_{10-\mathrm{x}} \mathrm{Sb}_{\mathrm{x}} \mathrm{Te}_{6}$ compound due to their low thermal and high electrical conductivity and potential for their use as high performance nano-thermoelectric materials. 


\section{EXPERIMENTAL SECTION}

$\mathrm{Tl}_{10-\mathrm{x}} \mathrm{S} b_{\mathrm{x}} \mathrm{Te}_{6}$ compound (where $\mathrm{x}=1,1.25,1.50,1.75,2$.) has been prepared by solid state reaction method from the $\mathrm{Sb}$ doped element with different concentration of respective elements ( $\mathrm{Tl}$ granules, 99.4\%; $\mathrm{Sb}$ powder, $99.5 \%$ and $\mathrm{Te}$ broken ingots, $>99.99 \%)$. Different Samples with different masses were measured between $60 \mathrm{mg}$ and $120 \mathrm{mg}$. $\mathrm{Tl}_{10}$ ${ }_{x} \mathrm{~S} b_{\mathrm{x}} \mathrm{Te}_{6}$ system was prepared by heating different elements of $\mathrm{Tl}, \mathrm{Sb}$ and $\mathrm{Te}$ in their stoichiometric molar ratio and kept in a silica tube (approx. $10^{-3} \mathrm{mbar}$ ) stored in an argon-filled glove box to prevent it from the reaction of other environmental elements. The silica tubes were coated under $\mathrm{H}_{2} / \mathrm{O}_{2}$ flame. All samples were gradually heated in a furnace with appropriate temperature. The profile for these compound is $(12 \mathrm{~h}-650 \mathrm{~K}-$ $24 \mathrm{~h}-650 \mathrm{~K} 60 \mathrm{~h}-650 \mathrm{~K}$ and cooled down to $550 \mathrm{~K}$ within 100 h). If the reaction mixture were inhomogeneous after heating, the material was again placed in a silica tube in the argon filled glove box and kept in heat furnace for one week. Keeping the process continues till desired homogeneous compound were obtained. The prepared ingot was then put in the Ball milling machine to produce nanoparticles of different sizes as mentioned latter.

\section{RESULT AND DISCUSSION}

Figure 1 shows the powder XRD spectrum of the thallium antimony telluride's compounds, $\mathrm{Tl}_{10-\mathrm{x}} \mathrm{Sb}_{\mathrm{x}} \mathrm{Te}_{6}$ with varying doping concentration $(\mathrm{x}=1,1.25,1.50,1.75,2)$. In the XRD patterns, the strongest intensity of the (213) diffraction peak around $31.80^{\circ}$ indicates a preferred oriented tetragonal phase with polycrystalline structure for all the doping concentrations in the host matrix. The peaks associated to the (130), (121), (220), 024), (006), (240), (413), (044) and (136) crystallographic planes were also observed. The XRD result implies that a single pure phase of $\mathrm{Tl}_{10-\mathrm{x}} \mathrm{Sb}_{\mathrm{x}} \mathrm{Te}_{6}$ is obtained in the present study. Further, the particle size of the prepared samples was estimated using Debye-Scherrer formula, $(\mathrm{D}=$ $0.9 \lambda / \mathrm{B} \cos \theta$ ) [21]. The crystallite size value of the prepared samples is in the range $(21-25 \mathrm{~nm})$ indicating that $\mathrm{Sb}$ incorporations in $\mathrm{TlSbTe}_{2}$ do not affect significantly its crystallite size. The XRD data are summarized in table 1.

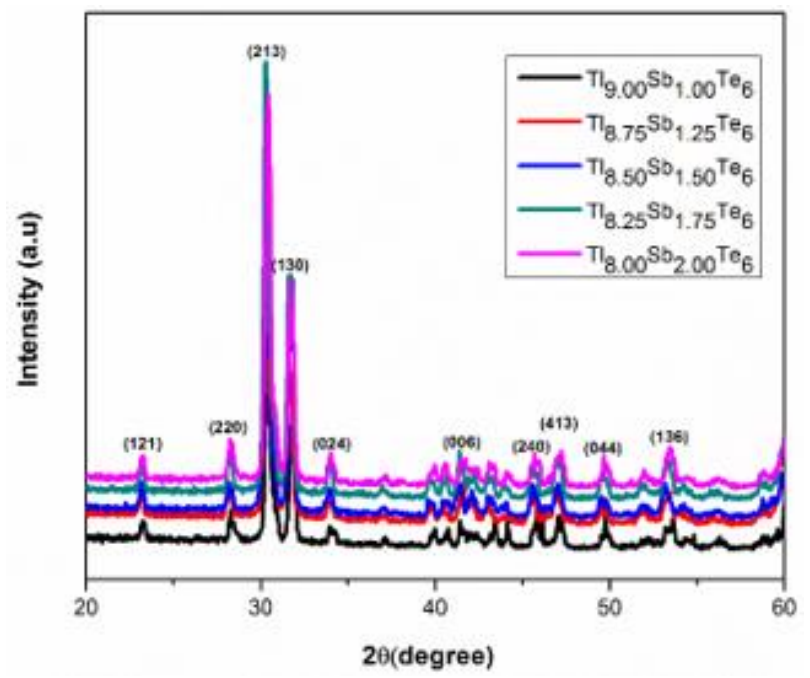

Figure 1. Room temperature powder XRD pattern of $\mathrm{Tl}_{10-}$ ${ }_{x} \mathrm{Sb}_{\mathrm{x}} \mathrm{Te}_{6}(\mathrm{x}=1,1.25,1.50,1.75,2)$
Table 1. Value of crystallite size and crystal system

\begin{tabular}{|c|c|c|c|}
\hline Sample & $\begin{array}{c}\text { Crystallite } \\
\text { size, } \\
\text { (nm) }\end{array}$ & $\begin{array}{c}\text { Lattice } \\
\text { constant } \\
\mathrm{a}, \mathrm{b}, \mathrm{c}=(\AA)\end{array}$ & $\begin{array}{l}\text { Volume } \\
\left(\AA^{3}\right)\end{array}$ \\
\hline $\mathrm{Tl}_{9} \mathrm{Sb}_{1} \mathrm{Te}_{6}$ & 25.247 & $\begin{array}{c}\mathrm{a}=\mathrm{b}= \\
8.8930 \\
\mathrm{c}=13.0050\end{array}$ & 1004.51 \\
\hline $\mathrm{Tl}_{8.75} \mathrm{Sb}_{1.25} \mathrm{Te}_{6}$ & 21.795 & $\begin{array}{c}\mathrm{a}=\mathrm{b}= \\
8.8450 \\
\mathrm{c}=13.0755 \\
\mathrm{a}=\mathrm{b}=\end{array}$ & 1023.95 \\
\hline $\mathrm{Tl}_{8.50} \mathrm{Sb}_{1.50} \mathrm{Te}_{6}$ & 21.170 & $\begin{array}{c}8.8250 \\
\mathrm{c}=13.0000\end{array}$ & 1013.45 \\
\hline $\mathrm{Tl}_{8.25} \mathrm{Sb}_{1.75} \mathrm{Te}_{6}$ & 21.118 & $\begin{array}{c}8.8100 \\
\mathrm{c}=13.0010\end{array}$ & 1009.09 \\
\hline $\mathrm{Tl}_{8} \mathrm{Sb}_{2} \mathrm{Te}_{6}$ & 21.455 & $\begin{array}{c}\mathrm{a}=\mathrm{b}= \\
8.8484 \\
\mathrm{c}=13.1625\end{array}$ & 1022.72 \\
\hline
\end{tabular}

EDX analysis whose carried out quantitative percentage to get of the elements present in the samples. For $\mathrm{Tl}_{9} \mathrm{Sb}_{1} \mathrm{Te}_{6}$ sample highly rich in thallium has $(69.9 \% \mathrm{Tl}, 25.8 \% \mathrm{Te}$, and $4.2 \% \mathrm{Sb}$ ). In Figure 2, the spectra show the $\mathrm{Tl}: \mathrm{Te}$ ratio and the $\mathrm{Sb}$ concentration appear in the compound.

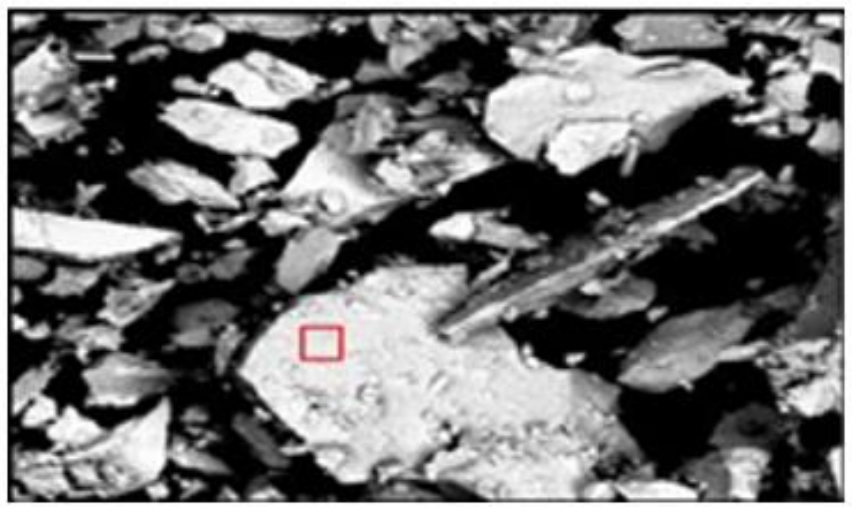

Figure 2. Image of scanning electron microscope

Table 2. Value of Volume and atomic percentage in compound

\begin{tabular}{ccc}
\hline Element & Volume \% & At \% \\
\hline $\mathrm{Sb}$ & 4.20 & 5.96 \\
$\mathrm{Te}$ & 25.84 & 34.96 \\
$\mathrm{Ti}$ & 69.96 & 50.09 \\
\hline
\end{tabular}

The electrical conductivity $\boldsymbol{\sigma}$, for $\mathrm{Tl}_{10-\mathrm{x}} \mathrm{Sb}_{\mathrm{x}} \mathrm{Te}_{6}$ samples (where $1 \leq \mathrm{x} \leq 2$ ) in the temperature range $300 \mathrm{~K}$ and $550 \mathrm{~K}$ is shown in Figure 3. Electrical conductivity decreases gradually with increasing temperature, shows similar trend to $\mathrm{Tl}_{9} \mathrm{BiTe}_{6}$ system. This behavior of our $\mathrm{Sb}$ doped is true in case of intrinsic semiconductors with $x=1$ as well as for doped semiconductors with $x$ up to 2.00 , like the compounds $\mathrm{Tl}_{10}$ ${ }_{x} \mathrm{Sn}_{\mathrm{x}} \mathrm{Te}_{6}$ and $\mathrm{Tl}_{10-\mathrm{x}} \mathrm{Bi}_{\mathrm{x}} \mathrm{Te}_{6}[6,8]$. The decreasing behavior of electrical conductivity with temperature indicates the p-type conductivity.

$\mathrm{Tl}_{9} \mathrm{Sb}_{1} \mathrm{Te}_{6}$ has the highest electrical conductivity of $698.7 \Omega^{-}$ ${ }^{1} \mathrm{~cm}^{-1}$ at $300 \mathrm{~K}$, which decreases gradually with increasing temperature, i.e. $664 \Omega^{-1} \mathrm{~cm}^{-1} 550 \mathrm{~K}$ (figure 3). The electrical conductivity for $\mathrm{Tl}_{10-\mathrm{x}} \mathrm{Sb}_{\mathrm{x}} \mathrm{Te}_{6}$ also decreases with increase in concentration of $x$. As an example in varying concentration of 
$x$ from 1 to 2 , the electrical conductivity, decreased from 698.7 $\Omega^{-1} \mathrm{~cm}^{-1}$ to $658.6 \Omega^{-1} \mathrm{~cm}^{-1}$ at $300 \mathrm{~K}$. Similarly at $550 \mathrm{~K}$, it decreased from $664 \Omega^{-1} \mathrm{~cm}^{-1}$ at $\mathrm{X}=1$ to $617.4 \Omega^{-1} \mathrm{~cm}^{-1}$ at $\mathrm{X}=2$.

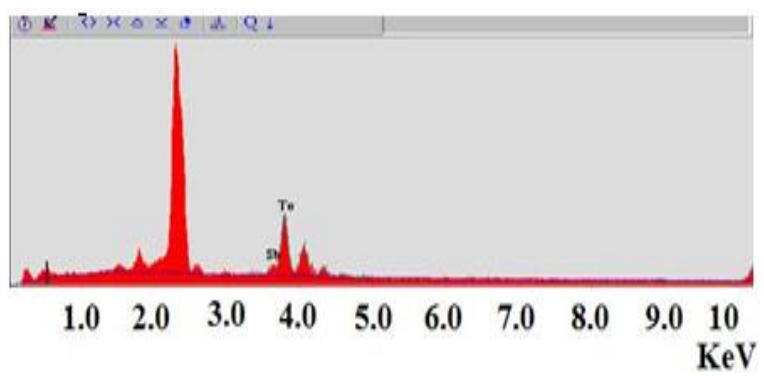

Figure 3. Image of energy dispersive X-ray spectroscopy

Table 3. The electrical conductivity at 300 and $550 \mathrm{~K}$ for all samples $(1.0 \leq \mathrm{x} \leq 2.0)$

\begin{tabular}{ccc}
\hline Sample & $\begin{array}{c}\text { Electrical } \\
\text { conductivity }\left(\Omega^{-}\right. \\
\left.{ }^{1} \mathrm{~cm}^{-1}\right) \text { at } 300 \mathrm{~K}\end{array}$ & $\begin{array}{c}\text { Electrical } \\
\text { Conductivity }\left(\Omega^{-}\right. \\
\left.{ }^{1} \mathrm{~cm}^{-1}\right) \text { at } 550 \mathrm{~K}\end{array}$ \\
\hline $\mathrm{Tl}_{9} \mathrm{Sb}_{1} \mathrm{Te}_{6}$ & 699 & 663 \\
$\mathrm{Tl}_{8.75} \mathrm{Sb}_{1.25} \mathrm{Te}_{6}$ & 694 & 659 \\
$\mathrm{Tl}_{8.50} \mathrm{Sb}_{1.50} \mathrm{Te}_{6}$ & 680 & 656 \\
$\mathrm{Tl}_{8.25} \mathrm{Sb}_{1.75} \mathrm{Te}_{6}$ & 674 & 642 \\
$\mathrm{Tl}_{8} \mathrm{Sb}_{2} \mathrm{Te}_{6}$ & 657 & 617 \\
\hline
\end{tabular}

Seebeck coefficient (S) measured for $\mathrm{Tl}_{10-\mathrm{x}} \mathrm{Sb}_{\mathrm{x}} \mathrm{Te}_{6}$ systems with different concentration of $\mathrm{Sb}(\mathrm{x}=1,1.25,1.50,1.75,2)$ is shown in figure 4. All samples show an increasing trend of Seebeck coefficient with increasing temperature for example, for sample $\mathrm{Tl}_{8} \mathrm{Sb}_{2} \mathrm{Te}_{6}$ Seebeck coefficient is increased from $78.66 \mu \mathrm{VK}^{-1}$ at $300 \mathrm{~K}$ to $125 \mu \mathrm{VK}^{-1}$ at $550 \mathrm{~K}$. In the same way for $\mathrm{Tl}_{9} \mathrm{Sb}_{1} \mathrm{Te}_{6}$ compound the Seebeck coefficient increased from $45 \mu \mathrm{VK}^{-1}$ at $300 \mathrm{~K}$ to $75 \mu \mathrm{VK}^{-1}$ at $550 \mathrm{~K}$.

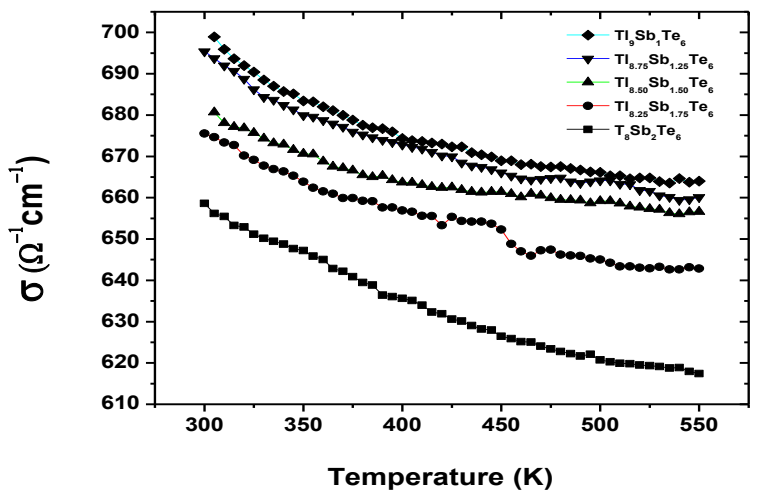

Figure 4. Electrical conductivity of T110-xSbxTe6 with $\mathrm{x}$ varying between 1 and 2

The Seebeck Coefficient significantly increased upon $\mathrm{Sb}$ doping. At $300 \mathrm{~K}$, it is enhanced from $44.1 \mu \mathrm{VK}^{-1}$ at $\mathrm{x}=1$ to $78.6 \mu \mathrm{VK}^{-1}$ at $\mathrm{x}=2$. Similarly, increasing $\mathrm{Sb}$ composition from 1 to $2, \mathrm{~S}$ increased from $78.66 \mu \mathrm{VK}^{-1} 125 \mu \mathrm{VK}^{-1}$ at $550 \mathrm{~K}$.

We have observed that the Seebeck coefficient linearly increases with temperature for all the composition studied here. P-type deficiency is frequently observed in heavy metal, telluride's, as found in $\mathrm{Tl}_{10-\mathrm{x}} \mathrm{Ln}_{\mathrm{x}} \mathrm{Te}_{6}$ series and $\mathrm{Tl}_{9} \mathrm{BiTe}_{6}$, causing a high number of charge carriers $\left(>10^{19} \mathrm{~cm}^{-3}\right)$ [7]. $\mathrm{Tl}_{10-}$ ${ }_{x} \mathrm{Ln}_{\mathrm{x}} \mathrm{Te}_{6}$ series $(\mathrm{Ln}=\mathrm{La}, \mathrm{Ce}, \mathrm{Pr}, \mathrm{Nd}, \mathrm{Sm}, \mathrm{Gd}, \mathrm{Tb})$ having almost similar trend of Seebeck coefficient of $\mathrm{Tl}_{10-\mathrm{x}} \mathrm{Sb}_{\mathrm{x}} \mathrm{Te}_{6}$ [7]. Increasing of Seebeck coefficient with temperature by the creation of a small energy band gaps can be easily excited from the valance band to conduction band [16].

The temperature dependencies with variation in concentration of dopant, can be attributed to the relationship between Seebeck coefficient, temperature and charge carrier concentration according to the following formula [21],

$S=T \frac{8 \pi^{2} k^{2}{ }_{B} m^{*}}{3 e h^{2}}\left(\frac{\pi}{3 n}\right)^{2 / 3}$

Here, $k_{B}$ is the Boltzmann constant, $e$ is electronic charge, $h$ is Planck constant, $m^{*}$ is effective mass, and $n$ is charge carrier concentration in system.

The above equation shows that $\mathrm{S}$ would depend on which dominated parameter in a particular situation and in specific system, Compounds with $x \geq 1$ is supposed to be p-type semiconductor as $\mathrm{Tl}_{9} \mathrm{SbTe}_{6}$ is formally an intrinsic semiconductor as observed from the experimental positive value of $S$.

As electrical conductivity, increases carriers concentration which is as per equation $\sigma=n e \mu$, where $\mu$ and $e=$ charge of carriers respectively, as mentioned above, $S$ has $n^{-2 / 3}$ dependence, $S$ and $\sigma$ are related inversely through $n$. The experimental results endorse that increased $\mathrm{x}$ causes $\sigma$ decreases for a given $\mathrm{Sb}$ due to decrease in $n$ (see Figure 3). Furthermore, as $T$ increases, $\sigma$ to decreases, because $\mu=\tau / \mathrm{m}^{*}$ where $\tau$ is the relaxation time, inversely related to temperature.

Table 4. Temperature dependence of the Seebeck coefficient of $\mathrm{Tl}_{10-\mathrm{x}} \mathrm{Sb}_{\mathrm{x}} \mathrm{Te}_{6}$ samples at 300 and $550 \mathrm{~K}$

\begin{tabular}{ccc}
\hline Sample & $\begin{array}{c}\text { Seebeck } \\
\text { coefficient }\left(\mu \mathrm{VK}^{-}\right. \\
1)\end{array}$ & $\begin{array}{c}\text { Seebeck } \\
\text { coefficient }\left(\mu \mathrm{VK}^{-}\right. \\
1\end{array}$ \\
\hline $\mathrm{Tl}_{9} \mathrm{Sb}_{1} \mathrm{Te}_{6}$ & 46.76 & at $550 \mathrm{~K}$ \\
$\mathrm{Tl}_{8.75} \mathrm{Sb}_{1.25} \mathrm{Te}_{6}$ & 50.47 & 82 \\
$\mathrm{Tl}_{8.50} \mathrm{Sb}_{1.50} \mathrm{Te}_{6}$ & 58.75 & 82.96 \\
$\mathrm{Tl}_{8.25} \mathrm{Sb}_{1.75} \mathrm{Te}_{6}$ & 60.78 & 84.5 \\
$\mathrm{Tl}_{8} \mathrm{Sb}_{2} \mathrm{Te}_{6}$ & 80.95 & 96.59 \\
\hline
\end{tabular}

A significant non-linearity electrical and thermal behavior is observed from $300-550 \mathrm{~K}$, signifying the decomposition of semiconducting network into non-metallic clusters which are supported by a study of the transport and thermal characteristics. This investigation further testifies that the semi-conducting states are suppressed with the doping of $\mathrm{Sb}$, obviously a clear evidence of increase of Seebeck co-efficient.

\section{POWER FACTOR}

The power factor, characterized by $\alpha^{2} \sigma$, shows overall ther moelectric performance of thallium antimony telluride. The $p$ ower factor increases with increasing temperature for all of th e samples. The increasing values of power factor for $\mathrm{Sb}$ dope $\mathrm{d}$ thallium telluride system are mainly attributed to increasing Seebeck coefficients. The Sb doped system show a power fac tor in the range from $1.31 \mu \mathrm{W}-\mathrm{cm}^{-1} \mathrm{~K}^{-2}$ to $9.8 \mu \mathrm{W}-\mathrm{cm}^{-1} \mathrm{~K}^{-2}$ at 30 $0 \mathrm{~K}$ and $550 \mathrm{~K}$ respectively. The samples with $\mathrm{x}=1,1.25$ and 1.50 show slight increase with temperature and aggregate at $\mathrm{s}$ 
ame point at $4.0 \mu \mathrm{W}-\mathrm{cm}^{-1} \mathrm{~K}^{-2}$ as shown in Figure 5. All Sb do ped samples investigated here shows better performance of $p$ ower factor as compared to un-doped system. $\mathrm{Tl}_{9} \mathrm{LnTe}_{6}$ series was reported that the doping of different elements i.e $(\mathrm{Ce}, \mathrm{Pr})$ in ternary group show different values of power factor in the range of 2.8-4.6 $\mu \mathrm{Wcm}^{-1} \mathrm{~K}^{-2}$ at $550 \mathrm{~K}$ [7]. Ternary group $\left(\mathrm{Tl}_{10} \mathrm{~S}\right.$ $\mathrm{nTe}_{6}$ ) substitute of $\mathrm{Sn}$ has reported the value of power factor a $\mathrm{t} \mathrm{x}=2.05$ are $3.6-4.9 \mu \mathrm{Wcm}^{-1} \mathrm{~K}^{-2}$ at $320 \mathrm{~K}$ and $685 \mathrm{~K}$ respecti vely [18]. Which is quite low value compared to the one repo rted in the present study, i.e. for $\mathrm{Tl}_{8} \mathrm{Sb}_{2} \mathrm{Te}_{6}$ power factor is 8.9 $\mu \mathrm{Wcm}^{-1} \mathrm{~K}^{-2}$ at $550 \mathrm{~K}$. This is the main goal and achievement of this research work to enhance the power factor and thermo electric properties in modified system of $\mathrm{Tl}_{10} \mathrm{Te}_{6}$ system.

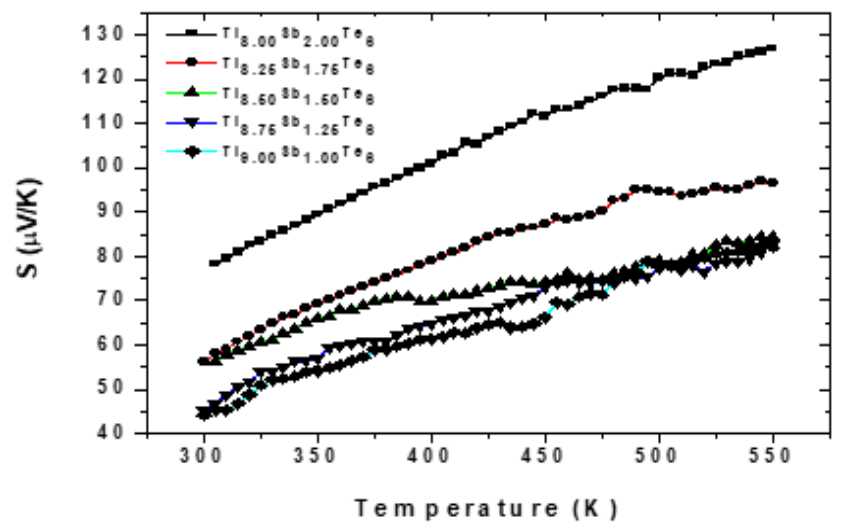

Figure 5. Seebeck coefficient of T110-xSbxTe6 with $x$ varying between 1 and 2

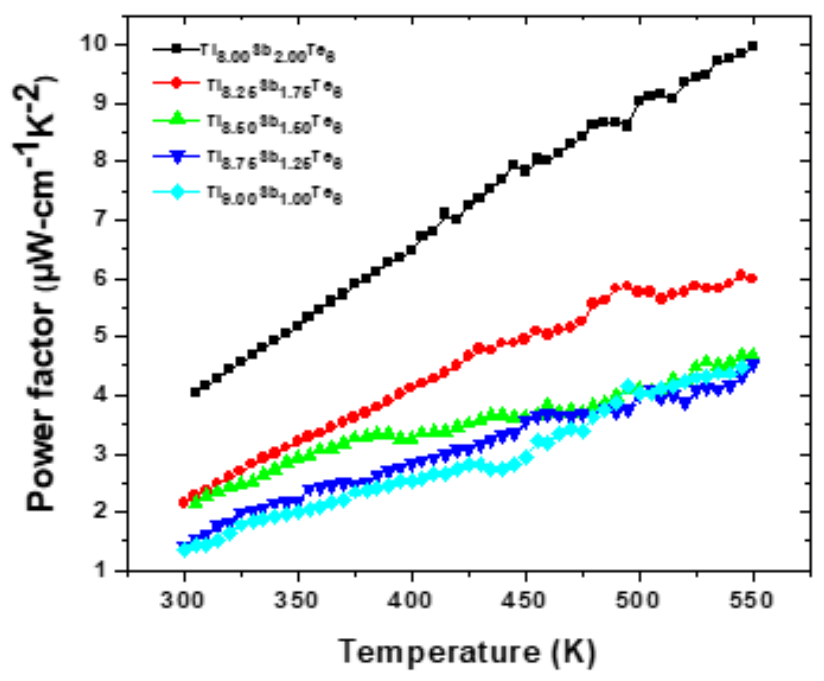

Figure 6. Power factor of T110-xSbxTe 6 with x varying between 1 and 2

\section{CONCLUSION}

We conclude that the structural and compositional analyses of $\mathrm{Tl}_{10-\mathrm{x}} \mathrm{Sb}_{\mathrm{x}} \mathrm{Te}_{6}$, shows tetragonal structure with space group $(I 4 / \mathrm{mcm})$, no impurities or secondary phases were found in th is system. We have concluded from the electrical and thermo electric properties that our system shows p-type behavior due to the Sb doping in binary thallium telluride group as they ha ve positive Seebeck coefficient in the whole range of tempera ture. There is substantial increment in the Seebeck coefficient with respected to temperature as well as Sb doping concentra tion in $\mathrm{Tl}_{10-\mathrm{x}} \mathrm{Sb}_{\mathrm{x}} \mathrm{Te}_{6}$, i.e. at $300 \mathrm{~K}$. We have observed ' $\mathrm{S}$ ' value $\mathrm{s}$ of $78.1 \mu \mathrm{VK}^{-1}$ for $\mathrm{Tl}_{8} \mathrm{Sb}_{2} \mathrm{Te}_{6}$ and $126 \mu \mathrm{VK}^{-1}$ at $500 \mathrm{~K}$ respec tively. Similarly the values of $\mathrm{S}$ at $300 \mathrm{~K}$ for $\mathrm{x}=1.00$ is $47 \mu \mathrm{V}$ $\mathrm{K}^{-1}$ and for $\mathrm{x}=2.00$ it increased up to $81 \mu \mathrm{VK}^{-1}$. On the other $\mathrm{h}$ and, at higher temperature, Seebeck coefficient at for $\mathrm{x}=1.00$ is $82.0 \mu \mathrm{VK}^{-1}$ and for $\mathrm{x}=2.00$ it increased up to $127 \mu \mathrm{VK}^{-1}$, th erefore, greater the ' $\mathrm{Sb}$ ' content lower the electrical conductiv ity and high the Seebeck coefficient. The high Seebeck coeffi cient in turn gives the enhanced value of power factor. A pro minent non-linear electrical and thermal behavior is observed in the temperature range studied here, signifying the decomp osition of the semiconducting network into non-metallic clust ers which are supported by a study of the transport and therm al behavior. This investigation further clarifies that the semi-c onducting behavior becomes weekend with the addition of $\mathrm{Sb}$, which is the clear evidence of increase of Seebeck co-efficien $t$ and suppression of metallic behavior. The results show here important information about the cluster co-existence, suppres sion of the metallic state with the addition of $\mathrm{Sb}$. The resistivi ty changes with $\mathrm{Sb}$ concentration but there is no structural ch anges observed. We conclude that the relative higher values o f 'Sb' based compound made them interesting for further stud $y$ and practical application, of high efficient thermoelectric ge nerators.

\section{REFERENCES}

[1] Rowe DM. (2006). Thermoelectrics Handbook: Macro to Nano, CRC Press. Taylor \& Francis Group, Boca Raton, FL, USA.

[2] Sharp JW, Sales BC, Mandrus DG, Chakoumakos BC. (1999). Thermoelectric properties of $\mathrm{Tl}_{2} \mathrm{SnTe}_{5}$ and $\mathrm{Tl}_{2} \mathrm{GeTe}_{5}$. Appl. Phys. Lett. 74: 3794-3796. https://doi.org/10.1063/1.124182

[3] Kurosaki K, Kosuga A, Muta H, Uno M, Yamanaka S. (2005). A high-performance thermoelectric bulk material with extremely low thermal conductivity. Appl. Phys. Lett. 87: 061919/13. https://doi.org/10.1063/1.2009828

[4] Sales BC, Chakoumakos BC, Mandrus D. (2000). Thermoelectric properties of thallium filled skutterudites. Phys. Rev. B 61: 2475-2481. https://link.aps.org/doi/10.1103/PhysRevB.61.247

[5] Harnwunggmoung A, Kurosaki K, Muta H, Yamanaka S. (2010). High-temperature thermoelectric properties of thallium-filled Skutterudites. Appl. Phys. Lett. 96. https://aip.scitation.org/doi/abs/10.1063/1.3430739

[6] Yamanaka S, Kosuga A, Kurosaki K. (2003). Thermoelectric properties of $\mathrm{Tl}_{9} \mathrm{BiTe}_{6}$. J. Alloys Comp. 352: 275-278. http://dx.doi.org/10.1016/S09258388(02)01114-3

[7] Guo Q, Chan M, Kuropatwa BA, Kleinke H. (2013). Enhanced thermoelectric properties of variants of $\mathrm{Tl}_{9} \mathrm{SbTe}_{6}$ and $\mathrm{Tl}_{9} \mathrm{BiTe}_{6}$ Chem. Mater. 25: 4097-4104. https://doi.org/10.1021/cm402593f

[8] Bryan A, Abdeljalil, Kleinke H. (2011). Phase range and physical properties of the thallium tin tellurides $\mathrm{Tl}_{10}$ ${ }_{x} \mathrm{Sn}_{\mathrm{x}} \mathrm{Te}_{6} \quad(\mathrm{x} \leq 2.2)$. Chem. Mater 6768-6772. https://doi.org/10.1016/j.jallcom.2011.03.182

[9] Guo Q, Assoud A, Kleinke H. (2014). Improved bulk materials with thermoelectric figure-of merit $>1$ : Tl10 xSnxTe6 and T110-xPbxTe6. Adv. Energy Mater. 4: 1400348/1-8. https://doi.org/10.1002/aenm.201400348 
[10] Wölfing B, Kloc C, Teubner J, Bucher E. (2001). High performance thermoelectric $\mathrm{Tl}_{9} \mathrm{BiTe}_{6}$ withan extremely low thermal conductivity. Phys. Rev. Lett. 86: 43504353.

https://link.aps.org/doi/10.1103/PhysRevLett.86.4350

[11] Kosuga A, Kurosaki K, Muta H, Yamanaka S. (2006). Thermoelectric properties of Tl-X-TeTl-X-Te $(\mathrm{X}=\mathrm{GeX}=\mathrm{Ge}, \mathrm{Sn}$, and $\mathrm{Pb}$ ) compounds with low lattice thermal conductivity. J. Appl. Phys. 99: 063705/1-4. https://doi.org/10.1063/1.2885113

[12] Sankar CR, Bangarigadu-Sanasy S, Assoud A, Kleinke H. (2010). Syntheses, crystal structures and thermoelectric properties of two new thallium tellurides: $\mathrm{Tl}_{4} \mathrm{ZrTe}_{4}$ and $\mathrm{Tl}_{4} \mathrm{HfTe}_{4}$. J. Mater. Chem. 20: 7485-7490. https//doi.org/ 10.1039/c0jm01363c

[13] Sankar CR, Guch M, Assoud A, Kleinke H. (2011). Structural, thermal, and physical properties of the thallium zirconium telluride $\mathrm{Tl}_{2} \mathrm{ZrTe}_{3}$. Chem. Mater. 23: 3886-3891. https:// doi.org/10.1021/cm200994t

[14] Bangarigadu-Sanasy S, Sankar CR, Assoud A, Kleinke H. (2011). Crystal structures and thermoelectric properties of the series $\mathrm{Tl}_{10-\mathrm{x}} \mathrm{La}_{\mathrm{x}} \mathrm{Te}_{6}$ with $0.2 \leq \mathrm{x} \leq 1.15$. Dalton Trans. 40: 862-867. https:// doi:10.1039/C0DT01151G

[15] Kosuga A, Kurosaki K, Muta H, Yamanaka S. (2006). Thermoelectric properties of Tl-X-TeTl-X-Te ( $\mathrm{X}=\mathrm{GeX}=\mathrm{Ge}, \mathrm{Sn}$, and $\mathrm{Pb}$ ) compounds with low lattice thermal conductivity. J. Appl. Phys. 99: 063705. https://doi.org/10.1063/1.2181427

[16] Bangarigadu-Sanasy S, Sankar CR, Schlender P, Kleinke H. (2013). Thermoelectric properties of $\mathrm{Tl}_{10-\mathrm{x}} \mathrm{Ln}_{\mathrm{x}} \mathrm{Te}_{6}$, with $\mathrm{Ln}=\mathrm{Ce}, \mathrm{Pr}, \mathrm{Nd}, \mathrm{Sm}, \mathrm{Gd}, \mathrm{Tb}, \mathrm{Dy}$, Ho and Er, and $0.25 \leq \mathrm{x} \leq 1.32$. J. Alloys Comp. 549(2013): 126-134. http://dx.doi.org/10.1016/j.jallcom.2012.09.023

[17] Najafi-Ashtiani, Bahari A, Hoseinzadeh S. (2018). "Study of structural, optical and electrical properties of $\mathrm{WO}_{3}-\mathrm{Ag}$ nanocomposite prepared by physical vapor deposition. Applied Physic A 124: 24. http://dx.doi.org/10.1007/s00339-017-1412-5

[18] Hosseinzadeh, Bahari A. (2017). n-type $\mathrm{WO}_{3}$ semiconductor as a cathode electrochromic material for ECD device. Journal of Materials Science: Materials in Electronics 28: 14446-14452. https://doi.org/10.1007/s11664-018-6199-4

[19] Hoseinzadeh, Ramezani AH. (2018). The effect of nitrogen structure, morphology and electrical resistance of tantalum by Ion implantation method. Journal of Inorganic and Organometallic Polymers and Materials 1443-1574. https://doi.org/10.1007/s10904-017-0769-4

[20] Hosseinzadeh, Bahari A. (2017). The injection of Ag nanoparticles on surface of $\mathrm{WO}_{3}$ thin film: enhanced electrochromic coloration efficiency and switching Response. Journal of Materials Science: Materials in Electronics 28: 14855-14863. https://doi.org/10.1007/s10854-017-7357-9

[21] Monshi A, Reza Monshi M. (2012). World Journal of Nano Science and Engineering 2: 154-160. https://doi:10.4236/wjnse.2012.23020

[22] Snyder GJ, Toberer ES. (2008). Complex thermoelectric materials. Nat. Mater. 7: 105-114. https://doi.org/10.1038/nmat2090 